\title{
A study on relationship between organizational structure and learning characteristics: A case study of revenue agency
}

\author{
Karim Tahernezhad $^{\mathrm{a}^{*}}$, Jamshid Salehi Sadaghiani ${ }^{\mathrm{b}}$ and Abbasali Ghaiyoomi ${ }^{\mathrm{a}}$
}

${ }^{a}$ Department of Management, Tehran North Branch, Islamic Azad University, Tehran, Iran ${ }^{b}$ Department of Management and Accounting, Allame Tabatabaee University, Tehran, Iran

\section{H R O N I C L E}

\section{Article history:}

Received October 20, 2012

Received in revised format

5 January 2013

Accepted 15 January 2013

Available online

January 172013

Keywords:

Learning organization

Organizational structure

Revenue agency

\begin{abstract}
A B S T R A C T
Learning is of the most challenging issues in most organizations and lack it could create serious problems for business development. In this paper, we present an empirical study to investigate the relationship between organizational structure and learning characteristics in a case study of revenue agency located in province of Alborz, Iran. Organizational structure includes five components of complexity, concentration, authority, formality and flexibility. A learning organization also includes five components including conceptual model, team learning, common goals, systematic vision and individual capabilities. There are 400 employees for the case study of our proposed study and we choose 196 people as a sample number. The proposed study of this paper uses structural equation modeling to survey the data using LIREL and SPSS software packages. Based on the results of this survey, we have concluded that there are some meaningful relationships between three variables of formality, complexity and authority on one side and learning capability from the other side. However, our study did not find any meaningful relationship between concentration and flexibility with organizational learning capability.
\end{abstract}

(C) 2013 Growing Science Ltd. All rights reserved.

\section{Introduction}

Learning is of the most challenging issues in most organizations and lack it could create serious problems for business development. Organizational learning plays an important role on coping with advances in technology in most firms and organizations. Kazanjian and Drazin (2012) gave an in debt explanation on organizational learning, knowledge management and creativity. They explained that any organization with no motivation to learn and improve its efficiency through learning will eventually fail. Learning also plays essential role in increasing government efficiency through reducing unnecessary costs. Organizational structure, on the other hand, is another important

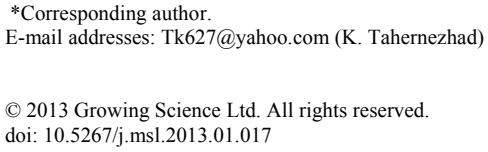


component of any organization. Any improvement in organizational structure can may also improve other organizational perspectives.

Khalghani et al. (2013) studied organizational structure, culture, and information technology as knowledge management (KM) infrastructural capabilities, and compared their significance and status quo in five medical research centers in Tehran, Iran. They reported that in terms of their status quo, the three studied KM enablers were at various conditions, with organizational culture having the best and IT the worst status. They also reported that organizational structure had the most significant impact on the effectiveness of knowledge management initiatives, while information technology gained the least perceived impact.

Ahmadi et al. (2012) investigated the relationship between organizational structure and organizational agility in some insurance companies. They reported that there was a significant relationship between organizational agility and two dimensions of organizational structure but they did not find any relationship between complexity and organizational agility. Darvish et al. (2013) investigated the impacts of intellectual capital on other components and their impacts on organizational learning capability. Their results of this survey indicated that human capital, relational capital and learning capabilities had positive influence on organizational performance, relational capital positively impacted learning capability and human capital influenced positively on relational capital.

Saeidipour et al. (2012) studied the impact of "emotional intelligence" on "organizational learning" among employees who worked for Jihad Agriculture organization of Isfahan, Iran and reported that emotional intelligence had a significant impact on organizational learning. Ali et al. (2012) examined the relationship between knowledge management practices and the organizational performance of Pakistan's telecommunication. Their result demonstrated that knowledge management practices had positive and significant influence on organizational performance, which reflected that organizations that prefer knowledge management practices got beneficial outcomes than their competitors did. Wei Phang et al. (2008) investigated organizational learning in eGovernment projects. In this paper, we present an empirical study to investigate the relationship between organizational structure and learning characteristics in a case study of revenue agency located in province of Alborz, Iran.

\section{The proposed study}

The proposed study of this paper investigates the relationship between organizational learning and structure. The case study of this paper includes all employees who work for revenue agency located in province of Alborz, Iran. The sample size is calculated as follows,

$n=\frac{N \times z_{\alpha / 2}^{2} \times p \times q}{\varepsilon^{2} \times(N-1)+z_{\alpha / 2}^{2} \times p \times q}$,

where $N$ is the population size, $p=1-q$ represents the yes/no categories, $z_{\alpha / 2}$ is CDF of normal distribution and finally $\varepsilon$ is the error term. Since we have $p=0.5, z_{\alpha / 2}=1.96$ and $N=400$, the number of sample size is calculated as $n=196$. Organizational structure includes five components of complexity, concentration, authority, formality and flexibility. A learning organization also includes five components including conceptual model, team learning, common goals, systematic vision and individual capabilities. The proposed study of this paper investigates the relationship between these two components using structural equation modeling.

\section{The results}

In this section, we present details of our investigation on structural equation modeling. We have applied LISREL software package to study the relationships and the results of our survey are summarized in Fig. 1 as follows, 


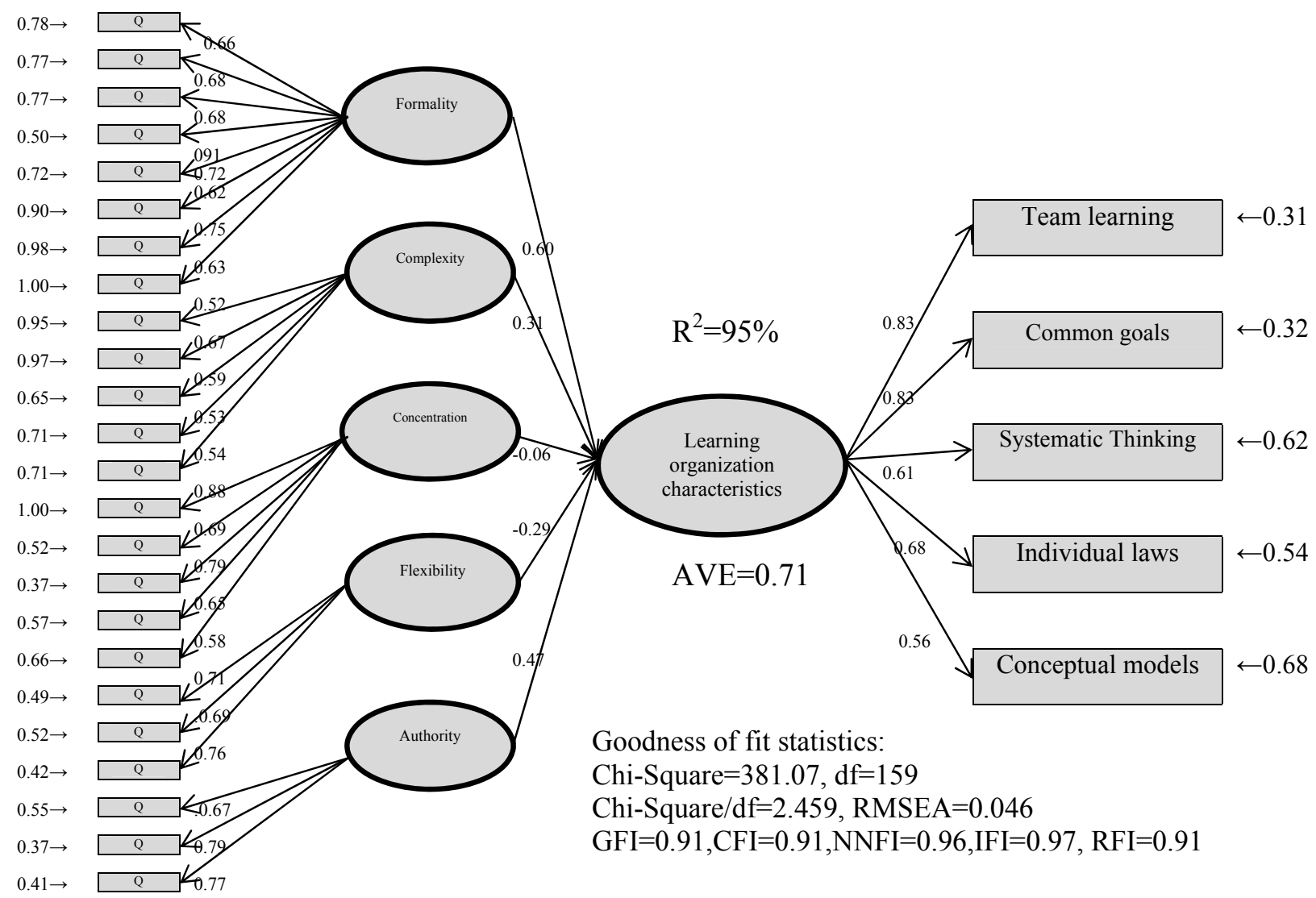

Fig. 1. The results of structural equation modeling

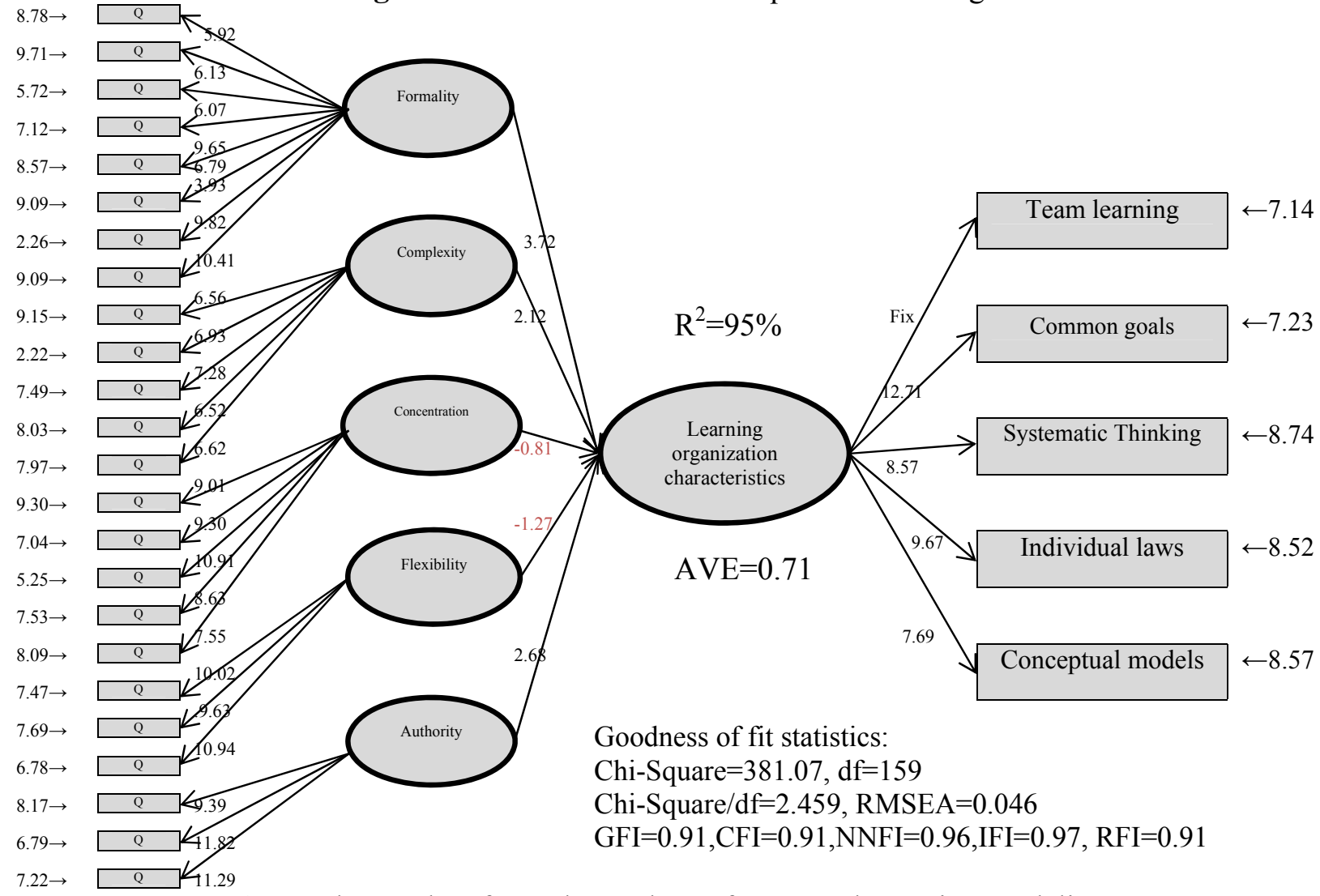

Fig. 2. The results of t-student values of structural equation modeling 
As we can observe from the results of Fig. 2, we can conclude that there are some meaningful relationships between three variables of formality, complexity and authority on one side and learning capability from the other side. However, our study did not find any meaningful relationship between concentration and flexibility with organizational learning capability.

\section{Conclusion}

In this paper, we have presented an empirical study to investigate the relationship between organizational structures components with organizational learning figures in an empirical study performed in one of revenue agencies located in province of Alborz, Iran. The results of our investigated have implied that there were some meaningful relationships between three variables of formality, complexity and authority on one side and learning capability from the other side. However, our study did not find any meaningful relationship between concentration and flexibility with organizational learning capability.

\section{References}

Ahmadi, S.A.A., Fathizadeh, A., Sadeghi, J., Daryabeigi, M., \& Taherkhani, L. (2012). A study on the relationship between organizational structure and organizational agility: A case study of insurance firm. Management Science Letters, 2(8), 2777-2788.

Ali, S.M., Qadus, A., \& Waseem, A., \& Zaman, K. (2012). Linking knowledge management practices and the organizational performance of Pakistan's telecommunication. Management Science Letters, 2(8), 2929-2938.

Darvish, H., Ahmadi, A.A., Kafashzadeh, A.R., \& Farid, S., \& Nejatizadeh, N.O. (2013). Investigating the effects of intellectual capital on organizational performance measurement through organizational learning capabilities. Management Science Letters, 3(1), 165-172.

Kazanjian, R.K., \& Drazin, R. (2012).Organizational Learning, Knowledge Management and Creativity. Handbook of Organizational Creativity, 547-568

Khalghani, A., Reshadatjoo, H., \& Iran-nejad-parizi, M. (2013). A study on organizational culture, structure and information technology as three KM enablers: A case study in five Iranian medical and healthcare research centers. Management Science Letters, 3(1), 147-158.

Saeidipour, B., Akbari, P., Marati Fashi, M.A. (2012). Study the effect of emotional intelligence on organizational learning staff, Case study: Jihad Agriculture Organization of Isfahan, Management Science Letters, 2(7), 2501-2510.

Wei Phang, C., Kankanhalli, A., \& Ang, C. (2008). Investigating organizational learning in eGovernment projects: A multi-theoretic approach. The Journal of Strategic Information Systems, $17(2), 99-123$ 